\title{
APLICAÇÃO DE SIMULADORES DE REALIDADE VIRTUAL E PROBLEM BASED LEARNING PARA O TREINAMENTO DE PROFISSIONAIS DA ÁREA DE SEGURANÇA
}

\author{
Antonio Valerio Netto*
}

Resumo: O artigo apresenta uma proposta para utilização de uma metodologia ativa baseada em Problem Based Learning (PBL) juntamente com o emprego de simuladores de realidade virtual (RV) com o objetivo de auxiliar no aprendizado e no treinamento de profissionais das áreas de segurança pública e privada. Determinadas técnicas, como a OMD (Observação, Memorização, Descrição) e a IDA (Identificar, Decidir, Agir), não são praticadas continuamente devido à dificuldade de se aplicar algum tipo de treinamento escalável, de baixo custo e que gere indicadores de desempenho adequados. Foram realizados testes de campo para validar a nova proposta e verificar a aderência da metodologia junto a público alvo. O propósito foi demonstrar que os módulos de treinamento baseado em PBL com simuladores de RV são capazes de compor uma plataforma de tecnologia educacional com o objetivo de aumentar o engajamento e melhorar a curva de aprendizagem do profissional de segurança.

Palavras-chave: Realidade virtual, simulador. Segurança pública e privada. Problem based learning. Treinamento de profissionais.

\section{Introdução}

Com o objetivo de promover uma qualificação adequada para um profissional da área de segurança (pessoas acima de 21 anos), foi realizado um estudo sobre o emprego de metodologias ativas (ROCHA; LEMOS, 2014), em oposição a uma aprendizagem passiva, baseada somente na transmissão de informações de forma escrita e/ou falada em uma sala de aula (VALERIO NETTO, 2016). É preterível que o aluno adulto assuma uma postura mais proativa, na qual ele resolva problemas e, com isto, consiga criar oportunidades para a construção do seu próprio conhecimento. Diante disso, entre os métodos da metodologia ativa existentes, a aprendizagem baseada na resolução de problemas (Problem Based Learning PBL) se mostra bastante aderente a este processo. O PBL inicia o treinamento criando a necessidade de resolver um problema não completamente estruturado, a exemplo do que

\footnotetext{
* * Doutor em Computação pela Universidade de São Paulo. Pesquisador em desenvolvimento tecnológico e extensão inovadora (DT) do CNPq e Coordenador de projeto pelo PIPE FAPESP.
} 
poderia ocorrer, fora de sala de aula (abordagem prática). Durante o processo de aprendizado, os alunos constroem o conhecimento do conteúdo e desenvolvem habilidades de resolução de problemas, bem como as competências de aprendizagem autodirigida (KWAN, 2000), provendo um ambiente propício para o desenvolvimento meta-cognitivo (HARYANI et al., 2014). O método PBL (Problem Based Learning) é uma metodologia de ensino e aprendizagem com larga utilização em faculdades e em outros níveis técnicos educacionais. Concebido no final dos anos 1960, o PBL emprega problemas da vida real (reais ou simulados) para iniciar, motivar e focar a aprendizagem de conhecimentos conceituais, procedimentais e atitudinais. O PBL é uma estratégia educacional, centrada no estudante, que o ajuda a desenvolver o raciocínio e a comunicação, habilidades essenciais para o sucesso em sua vida profissional. O estudante é constantemente estimulado a aprender e a fazer parte do processo de construção desse aprendizado (RIBEIRO, 2008).

$\mathrm{Na}$ área de segurança tanto pública quanto privada, determinadas técnicas, como é o caso da OMD (Observação, Memorização, Descrição) e da IDA (Identificar, Decidir, Agir), não são praticadas continuamente devido à dificuldade de se aplicar algum tipo de treinamento escalável, de baixo custo e que gere indicadores de desempenho adequados. Lembrando que o OMD é "Observar" com perfeição, "Memorizar" o que viu, e "Descrever" com veracidade. Essas habilidades fazem parte do "I" de "Identificar" da técnica IDA.

No caso da "Observação", para observar objetos, pode-se seguir a seguinte ordem didática: a forma geral do volume; avaliação das dimensões e proporções; estrutura geral, aspecto, estilo e cores; exame das diferentes partes componentes; e exame dos pormenores no interior destas partes. Para observar pessoas, pode-se seguir a seguinte ordem didática: caracteres distintivos; aspectos físicos gerais (sexo, cor, biótipo, idade, altura e peso); aspectos físicos específicos (obeso, calvo, etc.); etc. A "Memorização" é um conjunto de ações e reações voluntárias e metódicas que tem a finalidade de auxiliar na lembrança dos fatos. Existem vários sistemas de memorização como acrósticos, palavra-chave e concatenação. Por fim, a "Descrição" é a técnica de relatar com toda a veracidade as observações pessoais ou as impressões relatadas por outras pessoas. Em síntese, o objetivo final da OMD é "Observação + Memorização + Descrição = Identificação” (ROSA, 2014).

Com relação à IDA, o processo mental significa construir ideias em um pequeno espaço de tempo para antecipação do perigo, permitindo-lhe identificar e entender o ato de agressão que está ocorrendo. Sabendo que o tempo para reagir é curto, para responder a essa situação com razoável chance de êxito, o profissional precisa "Identificar", "Decidir" e “Agir”, isto é, identificar pela visão, sons, intuição ou outra forma. Posteriormente, decidir o 
que fazer, isto é, preparar-se mentalmente para tomar uma atitude. E por fim, agir, isto é, colocar em prática aquilo que planejou mentalmente, executar. Usualmente esses passos ocorrem nessa sequência, mas não é uma regra absoluta (MOREIRA; CORRÊA, 2002).

Diante do exposto, um caminho viável para atender tanto o processo de treinamento contínuo da OMD quanto da IDA, além de viabilizar o engajamento dos profissionais de segurança é a aplicação de roteiros situacionais baseado no PBL utilizando ambientes virtuais imersivos (simuladores). Pois são capazes de tornar o conhecimento mais prático permitindo aumentar os níveis de imersão, interação e envolvimento de cada profissional na hora do treinamento. Também é capaz de expor esse profissional a uma simulação virtual onde ele precisa tomar decisões de uma forma rápida e consegue estimular o seu poder de reação em um curto espaço de tempo, muitas vezes de milissegundos. Além disso, mantendo-se a crepetibilidade da execução dos módulos de treinamento, irá permitir que seu poder de reação, seja estimulado ao ponto de se tornar, um ato reflexo.

A utilização de simuladores baseado em tecnologia de Realidade Virtual (RV) tem o aspecto de envolver mais pontos de interação, envolvimento e imersão. Não somente para simular o uso da arma de fogo, mas também, para treinar a verbalização, postura corporal, etc. (VALERIO NETTO, 2015). Os simuladores de abordagem (segunda geração) foram criados para suprir a necessidade de treinamento onde à utilização de uma arma de fogo é a última opção diante de uma situação de conflito. Antes de atirar, existe todo um processo que vai desde a aplicação da técnica de OMD, passa pela verbalização, postura corporal, e posteriormente, como última opção, o disparo de uma arma de fogo. Este tipo de simulador está alinhado com a aplicação da metodologia do uso progressivo/seletivo da força, onde a ação deverá se dar de maneira compatível a gravidade da ameaça representada pela ação do infrator, sem se desviar do princípio da legalidade que norteia o processo de uma intervenção (SANDES, 2007).

\section{Simuladores de RV para área de segurança}

No início da utilização de simuladores no Brasil para treinamento na área de segurança, existia uma dúvida dos líderes sobre a eficiência e eficácia desse tipo de ferramenta utilizando a tecnologia de RV não imersiva. A RV não imersiva consiste na sensação de não-inclusão experimentada pelo usuário de um ambiente virtual, ou seja, ele não se sente como parte do ambiente. É considerado ambiente não imersivo, a visualização de imagens tridimensionais por meio de monitores ou projeções em anteparos, onde o usuário 
interage com os elementos do ambiente virtual por meio de dispositivos como teclado, joystick, ou mesmo, disparos de arma de fogo usando laser como é o caso de simuladores de tiro (Tori et al. 2006). As dúvidas versavam sobre questões relacionadas à qual seria o comportamento do profissional de segurança diante de uma situação simulada. Será que ele reagiria da mesma forma que uma situação real? Esse profissional acharia que era uma brincadeira ou se envolveria com a situação ao ponto de sua mente influenciar diretamente suas atitudes? Será que não poderia ser encarado como um videogame e não levar a sério o treinamento proposto? No caso, do simulador de tiro, existiria precisão dos disparos? Entre outras questões.

Os primeiros simuladores introduzidos no Brasil eram basicamente de tiro (primeira geração). Serviam apenas para treinar a destreza dos disparos com arma de fogo. Que inclusive, dentro do método do uso progressivo/seletivo da força é considerado a última opção de reação (VALERIO NETTO, 2006). No caso da segurança privada, o disparo com arma de fogo é responsável por menos de $1 \%$ das ocorrências operacionais. A justificativa para o emprego do simulador era simples, a questão era econômica e não educacional, isto é, a principal justificativa era que os simuladores de tiro poderiam diminuir os gastos com os projéteis reais, além de evitar acidentes fatais durante os treinamentos.

Pinto (2009) relatou que os agentes de segurança que recorreram ao uso de força letal, não tiveram a devida preparação para intervir em situações reais, tendo implicações no seu sucesso, que raramente excedia $50 \%$ do total de casos. Segundo a revisão bibliográfica realizada pelo autor na época, o mesmo concluiu que as situações de treino de tiro real não eram suficientemente representativas da realidade, porque focavam somente o uso da arma de fogo em condições estáticas, dando pouca ênfase à complexidade do conjunto de decisões que normalmente são solicitadas em uma ocorrência real. Os anos se passaram e foram realizados outros estudos sobre o uso da tecnologia de simuladores virtuais para área de segurança, além de testes de validação de campo que comprovaram que a tecnologia consegue atender as questões relacionadas ao treinamento continuado (FURUIE, 2013) (SILVA et al. 2013) (ALVES, 2014) (PEREIRA, 2014) (REIS et al., 2014) (ROSA; PAVANATI, 2015) (NETO; MARIA, 2015) (GOMES, 2016) (PINHEIRO et al., 2016) (DALL'AGNOL; PIRES, 2016) (PASSOS et al., 2016).

Com o emprego do simulador é possível treinar o método do uso progressivo/seletivo da força e de abaixar os custos com treinamentos em stands de tiro. Os simuladores virtuais de forma geral permitem aumentar a frequência dos treinamentos, o que impacta diretamente na memória motora/muscular do profissional. Também possibilita realizar essas atividades 
dentro das próprias bases operacionais o que evita deslocamento. Além disso, permite treinar equipes menores de profissionais em sessões de curta duração durante o expediente normal de trabalho sem precisar realizar horas extras. Esses simuladores podem ter módulos adicionais para medirem a curva de aprendizado de cada profissional, além de possibilitar o acompanhamento da evolução por treinamento realizado facilitando a geração de indicadores de desempenhos. Esses indicadores são importantes para os gerentes demonstrarem a eficiência dos treinamentos para os diretores dos departamentos de Recursos Humanos (RH), Gestão de Pessoas (GP), Desenvolvimento Humano e Organizacional (DHO), etc. Isto é importante para empresas privadas que possuem segurança orgânica (corporativa) e que precisam gerar indicadores de acompanhamento dos investimentos realizados na área de gestão da segurança.

\section{Metodologia}

Inicialmente foi realizado um levantamento de requisitos por meio de uma pesquisa exploratória que entrevistou profissionais de diversos setores da segurança tanto pública quanto privada. Esse tipo de pesquisa é utilizada quando se precisa definir um problema com maior precisão, identificar direcionamentos relevantes ou obter dados adicionais antes que se possa desenvolver uma abordagem (MALHOTRA, 2001) (MATTOS, 2005). Foram realizadas entrevistas não estruturadas com duração de 30 a 45 minutos envolvendo 102 profissionais de diversas hierarquias. Foram entrevistados diretores, gerentes, coordenadores e vigilantes de empresas privadas de segurança (transporte de valores, segurança pessoal, escolta armada, etc.). Capitães, tenentes, sargentos e soldados da polícia militar. Delegados e agentes policiais da polícia civil. Além de donos e instrutores das academias de formação de vigilantes.

Os principais requisitos levantados com essa pesquisa identificaram que o treinamento usando o simulador virtual deveria permitir que as atividades fossem realizadas em uma base ou posto de forma individual sem a presença do instrutor. E que precisaria treinar técnicas básicas, como por exemplo: OMD, IDA, varredura, etc. Essa plataforma educacional também deveria saber como o profissional reage ou não diante de uma situação de confronto para avaliar seu atual encargo. Deveria simular situações para que o profissional pudesse reagir, sendo que no caso das empresas privadas, o conteúdo poderia atender, além dos seguranças, os profissionais de facilities (portaria, controlador de acesso e até mesmo atendentes, entre outros) que não portam arma de fogo, mas que precisariam ter conhecimento básico de 
segurança para ajudar na observação e apoiar a segurança perimetral. Por fim, a plataforma educacional deveria ficar hospedada em cloud computing sem a necessidade de infraestrutura cara e suporte contínuo, pois a compra de um simulador é complicada devido ao custo de aquisição/suporte e sua depreciação. Com relação ao conteúdo, foi unanime junto aos entrevistados a questão envolvendo a prática no lugar de um conteúdo teórico. Gostariam de aprender vivenciando situações que permitam tomar decisões e terem uma reação.

Após a modelagem do sistema, houve o início do desenvolvimento do método ativo para geração dos roteiros de treinamento baseado em PBL. Em paralelo, também foi iniciada a criação da plataforma computacional. O novo simulador virtual utiliza um HMD (Head Mount-Display) para aumentar o nível de imersão e envolvimento. Diante disso, é possível ter acesso a uma tecnologia mais barata, do que adquirir um sistema complexo de $360^{\circ}$ (simulador de quatro a seis telas). Com isto, também é possível economizar com a logística de transporte, espaço físico, manutenção, etc.

O próximo passo foi criar os roteiros de treinamento específicos para cada tipo de simulador que serviram de base para a construção dos cenários 3D e vídeos 3D. Neste momento foi aplicado o conceito do PBL, gerando situações onde o usuário seria exposto e precisaria decidir qual seria a melhor forma de reação. Para o desenvolvimento da modelagem 3D foi utilizado o software UNITY. Para o simulador mobile, que utiliza o smartphone juntamente com o dispositivo Gear VR, foi empregado os conceitos de mobile learning e micro learning. Neste caso, os roteiros são curtos (2:30 minutos) e durante este roteiro são exibidas perguntas sobre a situação que está ocorrendo e como o profissional poderia reagir diante do fato. Durante a exibição do vídeo 3D, existem perguntas com possíveis respostas que são mostradas conforme o vídeo vai sendo executado. Existe um tempo limite para responder cada uma dessas questões. O usuário pode também optar por não responder. Ao final de cada módulo é exibida uma pontuação conforme as respostas que foram fornecidas durante a atividade. Estes dados são enviados via $3 \mathrm{G} / 4 \mathrm{G}$ para a plataforma cloud computing.

Da mesma forma, foi desenvolvido um roteiro específico baseado no PBL para o simulador standard considerando uma atividade onde uma situação de confronto foi modelada e o usuário terá que vivenciar para tomar suas decisões. Este tipo de exercício é acompanhado por um instrutor que orienta o profissional a melhor forma de reagir, etc. E depois, o avalia de forma subjetiva conforme sua reação e atitude durante o exercício. No caso dos cenários 3D, os mesmos foram construídos baseados na possibilidade de utilização do HMD, da interação por meio de voz, interação corporal utilizando tracker (sensor utilizado para rastrear a mão do usuário que pode, por exemplo, pegar em uma arma e realizar disparos) e o disparo com uma 
arma de fogo real. Todos os resultados são enviados para a plataforma cloud computing, de forma online (Figura 1).

Figura 1: Exibição de uma tela de indicadores dos usuários presente na plataforma cloud computing.

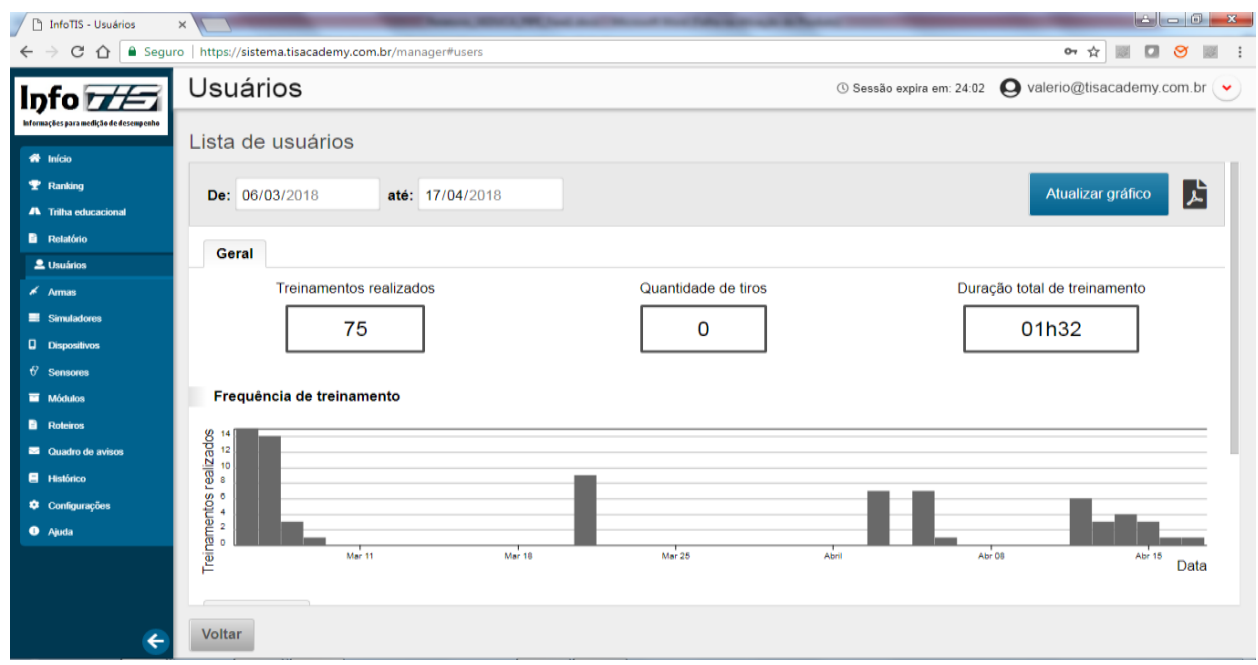

Fonte: próprio autor.

Em seguida foi desenvolvida a plataforma cloud computing utilizando tecnologia Java. Esta plataforma é responsável pelo envio e recebimento de dados vindos dos simuladores virtuais. Pela plataforma são cadastrados: os alunos, instrutores, trilha educacional (Figura 2), roteiros, entre outros. Além disso, é possível gerar relatórios e fazer a gestão de cada atividade didática (montagem da trilha educacional). Posteriormente, foi desenvolvido um módulo para medir o desempenho dos usuários por meio de indicadores usando BI (Business Inteligence). Também foi criado o protocolo de comunicação para 3G/4G/Wi-Fi responsável pela centralização dos dados vindo de diversos simuladores tanto mobile quanto standard localizados em locais diferentes.

Figura 2: Interface da edição da trilha educacional

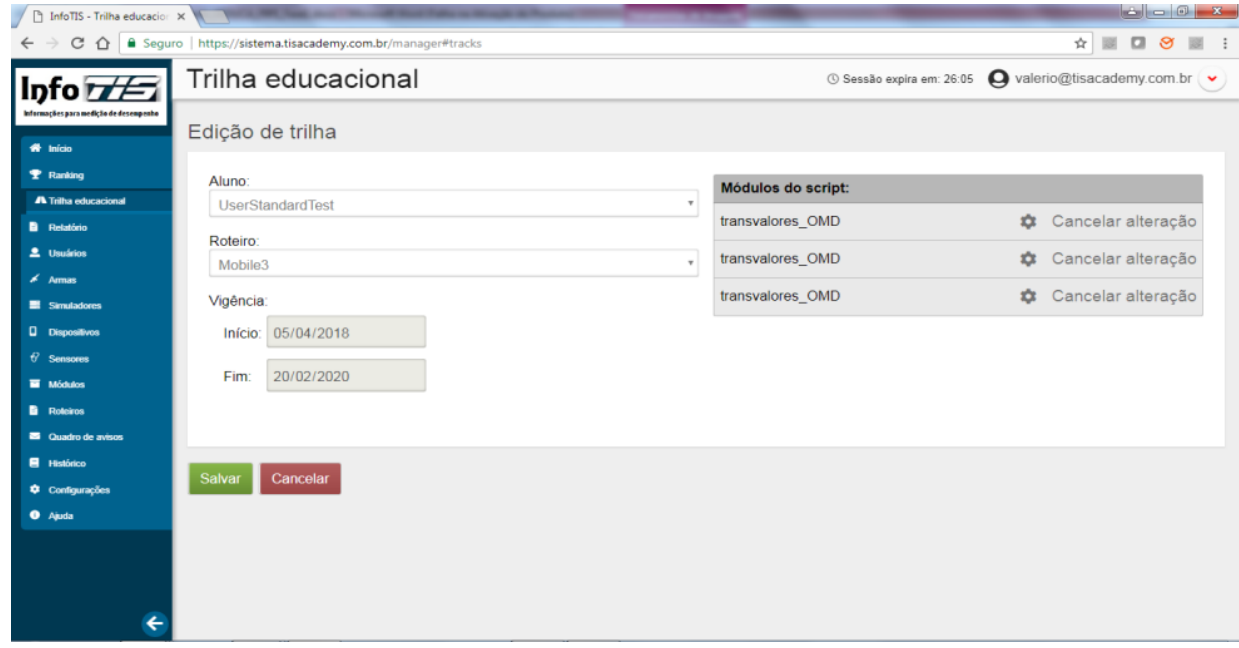

Fonte: próprio autor. 
Em linhas gerais, o desenvolvimento do sistema focou na concepção do simulador standard com o HMD utilizando o tracker e no simulador mobile usando smartphone e Gear VR. Também na criação de cenários 3D e vídeos 3D baseados no PBL para treinamento usando ambos simuladores, e por fim, no desenvolvimento da plataforma cloud computing. Após a fase de desenvolvimento experimental do sistema, deu-se início a fase de validação (interna e externa). Foram realizados testes de campo com 46 outras pessoas da área de segurança que não participaram das entrevistas iniciais para geração da modelagem na fase de visão do projeto (102 pessoas). O objetivo desses testes foi validar o conceito, isto é, se a aplicação do sistema realmente melhora o engajamento dos usuários. Além disso, também verificar o funcionamento adequado da plataforma tecnológica como um todo.

\section{Resultados e discussões}

Durante a fase da pesquisa exploratória com as 102 pessoas, foi constatado que o nível de disciplina quando é alto, acaba refletindo diretamente na questão do treinamento. No caso da segurança privada, os relatos direcionaram que a disciplina é uma habilidade em falta. A maioria dos entrevistados comentou que existem grandes problemas operacionais gerados a partir da falta de disciplina. Também foi detectado que para cada nicho do mercado privado (transporte de valores, escolta armada, patrimonial, segurança pessoal e grandes eventos), existe uma necessidade específica do que deveria ser treinado. Atualmente, o conteúdo de treinamento proposto é genérico e com ações pontuais de aprendizado (a maioria teórica). E que depois não se transformam em um processo de qualificação contínua (prático ou teórico). Apenas é realizado uma única vez e não se revisita o conhecimento para que o mesmo consiga ser absorvido pelas reações do profissional (memória muscular e ações instintivas).

$\mathrm{Na}$ fase de validação do sistema, foi aplicado o treinamento simulado junto a 46 profissionais da área de segurança. Eles realizaram, inicialmente, os exercícios do simulador mobile. Foram oito mulheres e 38 homens (Figura 3). Após participarem das sessões de treinamento, preencheram um questionário online usando o Google Forms com seis perguntas:

a) Hoje em dia, qual a sua opinião com relação aos treinamentos realizados om os seguranças? $(1$ = Péssimo / 6 = Excelente $)$

b) Você acredita que precisa mudar a forma como é treinado e medido o desempenho dos profissionais de operação da área de segurança? (1 = Não precisa $/ 6=$ Precisa urgentemente). 
c) Qual foi a primeira impressão com o uso do simulador mobile? (Diferente, Não sei opinar, Bem interessante, Nada demais).

d) Você teve dificuldade de usar o simulador mobile? (Sim, Não, Não sei opinar).

e) Ele é capaz realmente de ajudar a treinar as técnicas de OMD (Observar, Memorizar, Descrever) e IDA (Identificar, Decidir, Agir)? (Não sei opinar, Sim, Não).

f) Até que ponto você recomendaria o treinamento usando um simulador mobile para outra pessoa? $(1$ = Nada provável / 6 = Muito provável $)$.

Figura 3: Fase de validação do sistema com exercícios do simulador mobile.
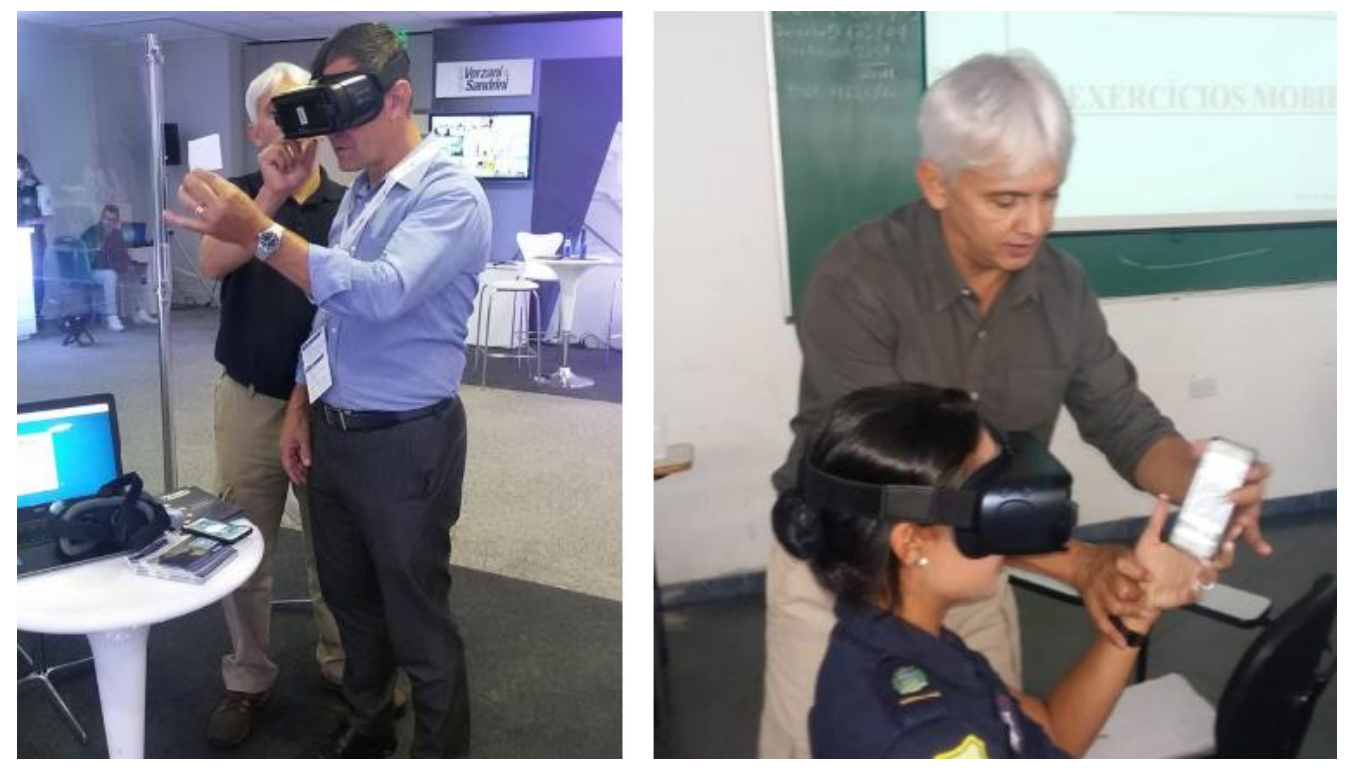

Fonte: próprio autor.

Na Figura 4 são apresentados os resultados das duas primeiras perguntas. Por meio dos resultados, foi constatado que a maioria dos profissionais entende que os treinamentos atualmente realizados na área de segurança não são adequados (22 pessoas), e que é necessário, uma mudança na forma de treinar os profissionais (36 pessoas). Na Figura 5 são exibidos os resultados referente à utilização do simulador mobile. As perguntas estavam relacionadas à qual foi à sua primeira impressão com o uso do simulador e se ele teve dificuldade em usá-lo. Por fim, na Figura 6, são apresentados os resultados sobre o questionamento se o simulador é mesmo capaz de ajudar a treinar as técnicas de OMD e IDA, e se ele recomendaria o treinamento com o simulador mobile para outra pessoa. 
Figura 4: Resultado referente à adequação dos treinamentos na área de segurança.
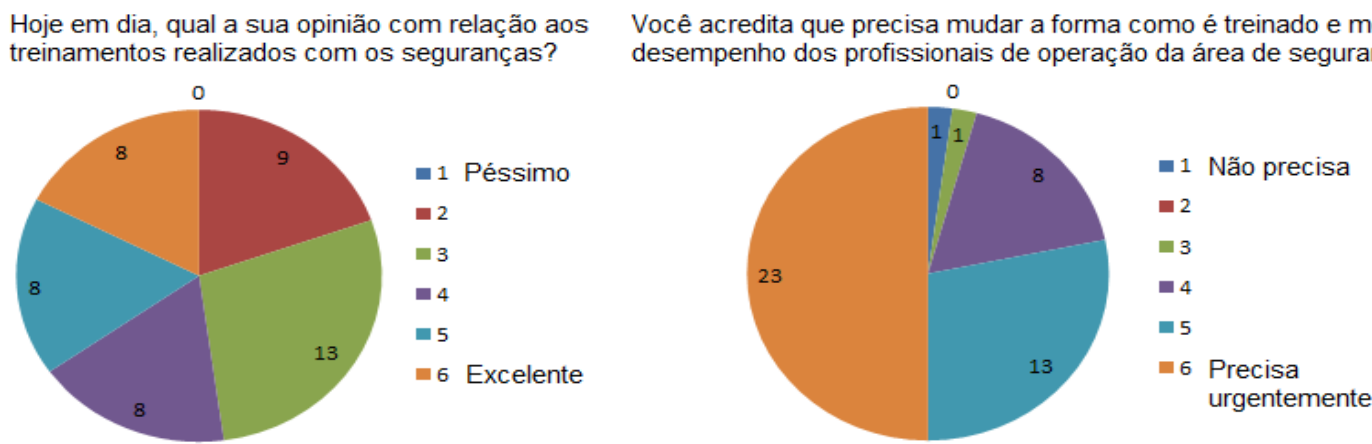

Fonte: próprio autor.

Figura 5: Conjunto de respostas referente à usabilidade do simulador mobile.
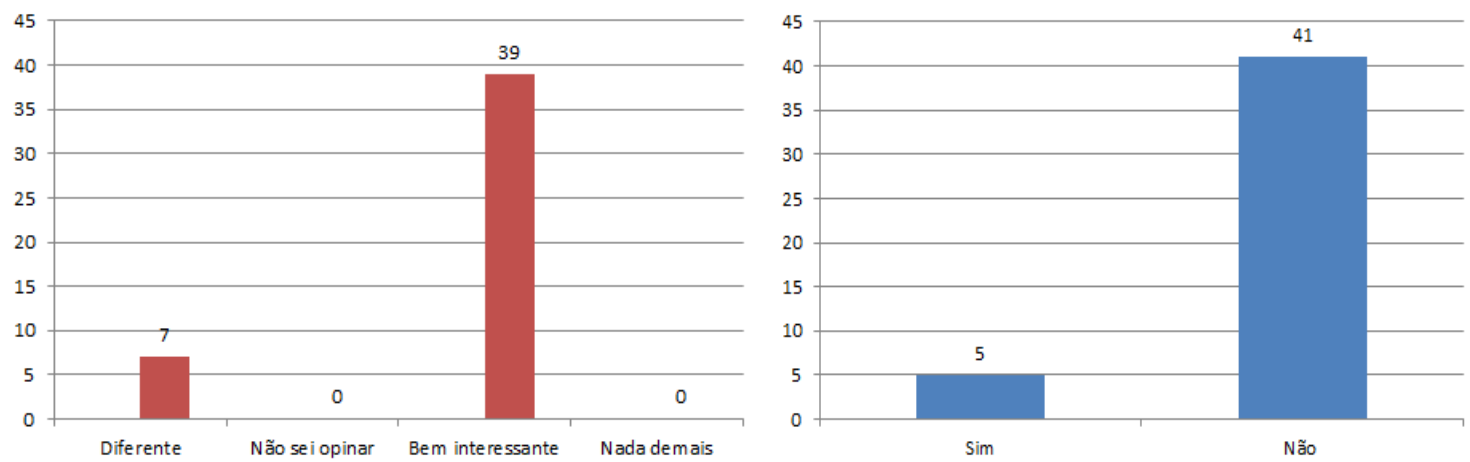

Fonte: próprio autor.

Figura 6: Respostas com relação ao emprego do simulador para atender as técnicas de OMD e IDA.

Ele é capaz realmente de ajudar a treinar as técnicas de OMD (Observar, Memorizar, Descrever) e IDA (Identificar, Decidir, Agir)?

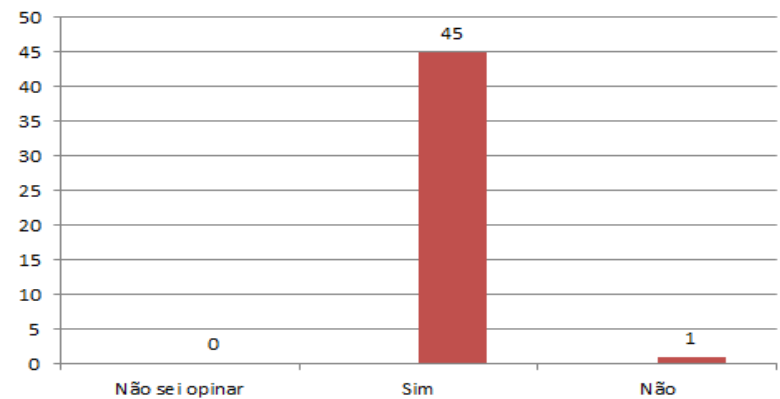
um simulador mobile para uma outra pessoa?

Fonte: próprio autor.

Após esta etapa inicial, os profissionais fizeram o treinamento com o simulador standard, e posteriormente, participaram de uma pesquisa exploratório com perguntas abertas para compreender a percepção de como eles se sentiram realizando a atividade. Foram executadas três baterias de exercícios previamente definidos com cada um dos 46 profissionais da área de segurança. O objetivo foi cruzar os dados da percepção que esse profissional teve de si mesmo ao final dos treinamentos, com as informações das avaliações 
realizadas pelo instrutor presente durante o treinamento usando o simulador standard. A meta foi compreender se por meio dos treinamentos virtuais, esses profissionais poderiam se autoavaliar, e também, se os resultados obtidos com a avaliação subjetiva do instrutor diante do desempenho de cada profissional; pudesse ser uma referência para uma avaliação objetiva diante dos resultados obtidos durante o treinamento simulado.

Nos testes realizados, a maioria dos profissionais teve sua percepção aumentada conforme as baterias de exercícios iam sendo realizadas, isto é, o desempenho da última bateria foi melhor do que a primeira, demonstrando claramente que ao longo de um processo de treinamento continuado, ocorreu uma melhora. Também, notou-se a questão da "sorte" de alguns profissionais na execução de determinados exercícios. Como eram realizadas três baterias de cada exercício, alguns profissionais se mostraram eficientes em determinada bateria isolada, mas em outras não conseguiam manter o mesmo desempenho. Por meio da execução dos exercícios foi possível identificar, inclusive, aqueles profissionais que possuem aprendizado rápido em relação aos outros. Também foi possível constatar que alguns profissionais não conseguiam executar adequadamente os exercícios propostos. Neste caso, eles deveriam treinar com uma frequência maior para conseguirem se adequar a um patamar mínimo exigido para aquela habilidade, no caso, o OMD.

\section{Considerações finais}

$\mathrm{Na}$ área de segurança uma atitude inadequada do profissional pode gerar uma repercussão negativa perante a sociedade, clientes, etc. Essas ocorrências de erros na abordagem podem, inclusive, serem suscetíveis a ações judiciais de reparação tanto de danos morais como trabalhista. Mesmo com diversas justificativas plausíveis o treinamento dos seguranças privados, por exemplo, é realizado em pouca quantidade e espaçado no tempo (uma vez por ano). Esta situação se dá, principalmente, devido aos altos custos com a logística de transporte, pagamento de hora-extra e com a mobilização de grupos de colaboradores que precisam ir até um stand de tiro para realizar as atividades práticas (manuseio de arma de fogo). Importante destacar que essas atividades tem um foco específico que é a destreza no manuseio do armamento e do disparo em si. Mesmo esse tipo de treinamento é falho, não permitindo grande interatividade, pois são utilizados alvos de papel que são inanimados e fixos. Os profissionais são colocados basicamente na frente de um alvo e isto não transmite uma sensação de realidade com a qual eles irão se defrontar no momento que ocorrer um sinistro no seu trabalho de rotina. Ainda ocorre um agravamento, pois existem 
muitos profissionais para treinar e poucos instrutores capacitados. Os stands de tiro estão cada vez mais distantes das bases de trabalho e em pouca quantidade. E atualmente para realizar treinamentos operacionais extras na própria empresa de segurança ou instituição de segurança pública, não existem ferramentas adequadas, o que o torna praticamente inviável.

O uso de simuladores de RV com conteúdos baseados em uma metodologia educacional ativa mostra-se adequado, pois permite melhorar o engajamento dos usuários. A criação de roteiros utilizando PBL para serem empregados nos simuladores de abordagem tem o aspecto de envolver mais pontos de interação e imersão. Além de facilitar a escalabilidade (ser usado por uma grande quantidade de pessoas), diminuir a necessidade de infraestrutura local, e praticamente, extinguir o custo de logística de transporte dos profissionais para realizar o treinamento. Foi possível observar nos testes práticos que os usuários tinham melhor entendimento dos conteúdos quando eram exigidos a tomarem decisões para resolverem as situações que eram expostos pelos roteiros. Isto os motivavam a ficar conectados a situação problema até o seu desfecho.

A maioria dos simuladores virtuais existentes no Brasil é de primeira geração, ainda focada somente na questão do aprimoramento do disparo da arma de fogo. Não possuem nenhum método de ensino específico, variando sua forma de uso, conforme o instrutor que está responsável pelo treinamento naquele momento. Alguns modelos desse tipo de simulador ainda possuem um grau de dificuldade na montagem e calibração, o que dificulta o deslocamento do equipamento para diversos locais de treinamento. Uma minoria é de segunda geração, os chamados de simuladores de abordagem, que foram criados para suprir a necessidade da atual postura da segurança que é a utilização de uma arma de fogo como última opção diante de uma situação de confronto (uso progressivo/seletivo da força). Contudo, em nenhum desses simuladores foram observados à inclusão de uma metodologia de ensino para o treinamento. Da mesma forma que na primeira geração, os fabricantes disponibilizaram apenas o equipamento, necessitando que cada instrutor crie seu próprio método de utilização do simulador junto aos alunos.

No Brasil, essa dependência do instrutor gerar conteúdo didático, acabou criando uma grande dificuldade na adoção dos simuladores no processo de qualificação e avaliação continuada dos profissionais de segurança pública e privada. Durante os testes, foi observado que os usuários precisavam se envolver com o assunto abordado durante o treinamento, pois apenas dessa forma, conseguiam abstrair e compreender como aplicá-lo na sua rotina diária de trabalho. Diferente do processo de aprendizagem onde novos conhecimentos são adquiridos, o treinamento, de forma geral, é empregado para aprimorar um conhecimento já aprendido. Isto 
é, esse conhecimento necessita continuamente ser revisitado para que o profissional consiga executar a ação de forma intuitiva. A repetição é fundamental para este aprimoramento. Quanto mais treinar a atitude, mais ficará competente. Se o profissional não entender que está recebendo o conhecimento para que as suas habilidades, o torne mais produtivo e competente, dificilmente irá valorizar o processo de qualificação.

É importante destacar que um treinamento continuado é fundamental para permitir que o profissional exerça adequadamente suas atividades, pois gera uma segurança mental e a real compreensão de sua capacidade de reação diante de uma situação de risco. Com um simulador virtual utilizando PBL, não se treina somente a destreza motora (memória muscular), mas sim, a capacidade mental de reação instintiva. Ademais, é importante que em uma situação de confronto, a mesma seja conduzida para uma ação conclusiva que não necessite do uso de força extrema. Por exemplo, uma situação de confronto com a adrenalina em alta e com pouca preparação, provavelmente, terá um desfecho inadequado. Os simuladores virtuais permitem um treinamento mais efetivo, propiciando um envolvimento psicológico maior com a ação, passando uma sensação de realidade, aonde o recuo da arma, o som, o cenário 3D, "transporta" o profissional de segurança para um momento realístico. O emprego dos simuladores de RV mobile propõe uma completa quebra de paradigma no processo de treinamento contínuo. Além disso, é importante lembrar que os simuladores podem suprir a necessidade da atual doutrina da área de segurança que é a utilização de uma arma de fogo como última opção diante de uma situação crítica.

Como impacto para a sociedade, o emprego de tecnologias educacionais visa melhorar a qualificação de guardas municipais, policiais civis e militares (federal e estadual) no que tange a abordagem junto à população possibilitando uma diminuição de um confronto violento, como um disparo de arma de fogo. Isto gera um número menor de vítimas fatais, ou mesmo, hospitalizadas (sobrecarga do serviço público de saúde), além de evitar o afastamento desses profissionais de segurança da sua rotina de trabalho. Pois quando ocorre uma situação de confronto com arma de fogo, existe um processo interno de sindicância, inclusive com o afastamento do profissional envolvido com a ocorrência, de seu trabalho diário. Arma de fogo mata ou fere; e essa arma de fogo na mão de pessoas despreparadas causa um prejuízo moral e social de altíssimo impacto.

A pesquisa realizada foi importante para validar na prática, se a aplicação de módulos de treinamento baseado em PBL, poderia ser capaz de compor uma plataforma educacional usando simuladores virtuais; visando aumentar o engajamento e melhorar a curva de aprendizado do profissional de segurança. Por meio dessa plataforma se pretende, 
futuramente, medir o desempenho e a eficácia das atividades dos profissionais com o objetivo de personalizar o aprendizado.

\title{
Agradecimentos
}

Ao apoio do CNPq (Conselho Nacional de Desenvolvimento Científico e Tecnológico), por meio do seu programa de Desenvolvimento Tecnológico e Extensão Inovadora (DT) e ao programa de Pesquisa Inovativa em Pequenas Empresas (PIPE) da FAPESP (Fundação de Amparo à Pesquisa do Estado de São Paulo).

\section{APPLICATION OF VIRTUAL REALITY SIMULATORS AND PROBLEM BASED LEARNING FOR THE TRAINING OF PROFESSIONALS OF THE SECURITY}

\section{AREA}

\begin{abstract}
The article presents a proposal for the use of an active methodology based on Problem Based Learning (PBL) together with the use of virtual reality simulators (VR) with the objective of assisting in the learning and training of professionals in the areas of public and private security. Certain techniques, such as OMD (Observation, Memorization, Description) and IDA (Identify, Decide, Act), are not continually practiced because of the difficulty of implementing some kind of scalable, low cost training and generating adequate performance indicators. Field tests were carried out to validate the new proposal and verify the adherence of the methodology to the target audience. The purpose was to demonstrate that the PBL-based training modules with RV simulators are able to compose an educational technology platform with the goal of increasing engagement and improving the learning curve of the safety professional.
\end{abstract}

Keywords: Virtual reality. Simulator. Public and private security. Problem based learning. Professional training.

\section{Referências}

ALVES, D. O emprego da realidade virtual no treinamento policial para o enfrentamento de criminosos com ênfase nos chamados encontros mortais: uma abordagem baseada na teoria geral de sistemas. Tese de Doutorado. Universidade Federal de Santa Catarina. 2014.

DALL'AGNOL, R. P.; PIRES, E. A.; SANTOS, S.; MACHADO, G. J. C.; RUSSO, S. L. Mapeamento tecnológico de patentes de simuladores de tiro. Cadernos de Prospecção, v.9, n.1, pp. 70-76, 2016.

FURUIE, L. M. A. Melhoria na segurança pública com treinamento continuado do policial militar em estande de tiro modelo. 2013. Disponível em 
<http://www.acervodigital.ufpr.br/bitstream/handle/1884/30433/R\%20-\%20D\%20-

\%20LESLY\%20MIKI\%20ABE\%20FURUIE.pdf>. Acesso em: 13 mar. 2018.

GOMES, P. A Simulação nos Desafios do Futuro para a Operacionalidade das Forças de Segurança: o seu Emprego na Guarda Nacional Republicana. 2016. Disponível em <https://comum.rcaap.pt/bitstream/10400.26/14632/1/TII_Maj\%20GNR \%20Gomes_A\%20Simula\%C3\%A7\%C3\%A3o\%20na\%20GNR_Final.pdf >. Acesso em: 03 mar. 2018.

HARYANI, S.; PRASETYA, A. T.; PERMANASARI, A. Developing Metacognition of Teacher Candidates by Implementing Problem Based Learning within the Area of Analytical Chemistry. International Journal of Science and Research (IJSR), v. 3, n.6, pp.1223-1229, jun. 2014.

KWAN, C. Y. What is Problem-Based Learning (PBL)? It is magic, myth and mindset.

Centre for Development of Teaching and Learning, v. 3 n. 3, aug. 2000.

MALHOTRA, N. K. Pesquisa de marketing: uma orientação aplicada. 3. ed., Porto Alegre: Bookman, 2001.

MATTOS, L. C. A entrevista não-estruturada como forma de conversação: razões e sugestões para sua análise. Revista de Administração Pública - RAP, v.39, n.4, 2005.

MOREIRA, C. N.; CORRÊA, M. V. Manual de prática policial. Polícia Militar de Minas Gerais, 2002. Disponível em < http://www.errogrupo. com.br/v4/pt/wpcontent/uploads/2013/07/Manual-de-pr\%C3\%A1tica-policial-Resolucao_3664.pdf >. Acesso em: 20 mar. 2018.

NETO, D; MARIA, J. O uso do simulador de tiro na formação e adestramento do agente de segurança da presidência da república. 2015. <Disponível em https://riuni.unisul.br/handle/12345/397>. Acesso em: 03 mar. 2018.

PASSOS, C. A.; SILVA, M. H.; MÓL, A. C.; CARVALHO, P. V.; LIMA, F. A.; ROCHA, T. L. Uso de simulador virtual para treinamento de agentes em ações de proteção radiológica em grandes eventos. 2016. Disponível em <http://carpedien.ien. gov.br/handle/ien/1826>. Acesso em: 13 mar. 2018.

PEREIRA, C. M. G. Realidade virtual como ferramenta para treino policial: desenvolvimento de um simulador para treino de tiro ao alvo, Dissertação de Mestrado. Universidade de Aveiro, 2014.

PINHEIRO, E. B.; GOMES, G. A.; COUTINHO, E. F.; VIDAL, C. A.; NETO, J. B. C. Requirements for Development of a Low Cost Portable Simulator for Shooting Skill Training. Virtual and Augmented Reality (SVR), pp. 234-238, 2016.

PINTO, P. R. P. Treino de tiro: análise de situações de treino em contexto policial, Tese de Doutorado. Universidade da Beira Interior, 2009. Disponível em <https://ubibliorum.ubi.pt/handle/10400.6/1805>. Acesso em: 20 mar. 2018. 
REIS, A. V.; GONÇALVES, B.; GARCIA, F. L. S. Um Estudo em Interfaces Tangíveis: Avaliação de Usabilidade de um Simulador de Armas de Fogo. Human Factors in Design, v.3, n.5, pp. 4-22, 2014.

RIBEIRO, L. R. C. Aprendizagem baseada em problemas (PBL): uma experiência no ensino superior. São Carlos: Edufscar, 2008.

ROCHA, H. M.; LEMOS, W. D. Metodologias ativas: do que estamos falando? Base conceitual e relato de pesquisa em andamento. IX Simpósio Pedagógico e Pesquisas em Comunicação. Resende: Associação Educacional Dom Boston, 12, 2014.

ROSA, M. Uma análise das técnicas operacionais de inteligência no contexto das operações de inteligência de segurança privada. Segurança Privada-Unisul Virtual, 2014. Disponível em < http://www.riuni.unisul.br/handle/12345/369>. Acesso em: 20 mar. 2018.

ROSA, A. J. P.; PAVANATI, I. A utilização da realidade virtual e aumentada na formação dos policiais militares em Santa Catarina. Revista Ordem Pública, v.7, n.2, pp. 37-51, 2015.

SANDES, W. F. Uso não-letal da Força na Ação Policial: Inteligência, Pesquisa, Tecnologia e Intervenção Sócio-Educativa. Fórum Brasileiro de Segurança Pública, 24, 2007.

SILVA, L. J. S.; MIZDAL, T. B.; NETTO, L. F.; FRAZZON, A. T. A.; SCHARDONG, G. G., POZZER, C. T.; PASSOS, E. B. Arquitetura para o desenvolvimento de um Ambiente de Simulação de Tiro. XII Simpósio Brasileiro de Jogos e Entretenimento Digital, 2013.

TORI, R., KIRNER, C.; SISCOUTTO, R. A. Fundamentos e tecnologia de realidade virtual e aumentada. Editora SBC, pp. 2-21, 2006.

VALERIO NETTO, A. Development of a security training system based on interactive multimedia. Revista IEEE América Latina, São Paulo, v. 4, n.5, pp. 379-384, 2006.

VALERIO NETTO, A. Application of Interactive Technology for Training in the Security Area. Virtual and Augmented Reality (SVR), pp. 127-132, 2015.

VALERIO NETTO, A. Tecnologia de treinamento interativo para diminuição de custos e aumento de desempenho de profissionais da área de segurança privada e pública. II Coletânea ABSEG de Segurança Empresarial, 2016. 